\title{
The Effects of Hip Mobilizations on Patient Outcomes: A Critically Appraised Topic
}

\author{
Erica S. Albertin, Emilie N. Miley, James May, Russell T. Baker, and Don Reordan
}

\begin{abstract}
Clinical Scenario: Hip osteoarthritis currently affects up to $28 \%$ of the population, and the number of affected Americans is expected to rise as the American population increases and ages. Limited hip range of motion (ROM) has been identified as a predisposing factor to hip osteoarthritis and limited patient function. Clinicians often apply therapy techniques, such as stretching and strengthening exercises, to improve hip ROM. Although traditional therapy has been recommended to improve hip ROM, the efficiency of the treatments within the literature is questionable due to lack of high-quality studies. More recently, clinicians have begun to utilize joint mobilization and the Mulligan Concept mobilization with movement techniques to increase ROM at the hip; however, there is a paucity of research on the lasting effects of mobilizations. Given the difficulties in improving ROM immediately (within a single treatment) and with long-lasting results (over the course of months), it is imperative to examine the evidence for the effectiveness of traditional therapy techniques and more novel manual therapy techniques. Focused Clinical Question: Is there evidence to suggest manual mobilizations techniques at the hip are effective at treating hip ROM limitations? Summary of Clinical Findings: 5 Randomized Controlled Studies, improved patient function and ROM with the Mulligan concept, high velocity low amplitude improved. Clinical Bottom Line: We found moderate evidence to suggest favorable outcomes following the use of hip mobilizations aimed at improving hip ROM and patient function. Strength of Recommendation: Strength of the studies identified are 1B.
\end{abstract}

Keywords: Mulligan Concept, hip manual therapy, patient function

\section{Clinical Scenario}

Hip osteoarthritis affects up to $28 \%$ of the population and is expected to rise as the American population ages. ${ }^{1,2}$ Limited hip range of motion (ROM) has been identified as a predisposing factor to hip osteoarthritis and limited patient function (ability to complete pain-free daily activities with achieving normal ranges of motion). ${ }^{3,4}$ Clinicians often apply traditional therapy, such as stretching and strengthening exercises, to improve hip ROM. ${ }^{5}$ Although traditional therapy has been recommended to improve hip ROM, the efficiency of the treatments is questionable. ${ }^{3-8}$ More recently, clinicians have also begun to utilize joint mobilization and the Mulligan Concept (MC) mobilization with movement (MWM) techniques to increase $\mathrm{ROM}^{3-8}$; however, there is a paucity of research on the lasting effects of mobilizations. Given the difficulties in improving ROM immediately and with longlasting change, it is imperative to examine the evidence for the effectiveness of traditional therapy techniques and more novel manual techniques.

\section{Focused Clinical Question}

Is there evidence to suggest manual joint mobilizations for the hip are effective at treating hip ROM limitations?

Albertin is with the Kinesiology Department, Goshen College, Goshen, IN. Miley, May, and Baker are with the Department of Movement Sciences, University of Idaho, Moscow, ID. Reordan is with Jacksonville Physical Therapy, Jacksonville, OR. Albertin (ealbertin@goshen.edu) is corresponding author.

\section{Summary of Search, "Best Evidence" Appraised, and Key Findings}

- The literature was searched for research of level 2 evidence or higher that investigated the effects of mobilizations on the hip joint within the healthy or nonsurgical patient population and compared mobilizations with other forms of treatments.

- The search of the literature provided 5 randomized control trial studies, which met the inclusion criteria and were included. ${ }^{3,5-8}$

- Three studies compared use of the MC on the hip joints to traditional therapy treatments, ${ }^{3,7,8}$ one study compared highvelocity low-amplitude (HVLA) mobilizations to the hip joint to a grade 1 mobilization, ${ }^{5}$ and one study compared HVLA on the sacroiliac joint to traditional treatments. ${ }^{6}$

- The 3 studies that utilized the MC reported improved patient function and ROM compared with stretching of the hips..$^{3,7,8}$

- The study that utilized HVLA reported immediate improvements in ROM and pain. ${ }^{5}$

\section{Clinical Bottom Line}

We found moderate evidence to suggest favorable outcomes following the use of hip mobilizations aimed at improving hip ROM and patient function (Table 1); the evidence suggests that mobilizations can be used to decrease pain, while also leading to increased ROM and patient function. ${ }^{3,5-8}$ The outcomes from traditional treatments (eg, stretching, exercises, or heat therapy) differed from the use of novel mobilization techniques. These findings suggest the utilization of the novel mobilization techniques is more effective than traditional therapies. The evidence included also suggests that the MC MWM techniques may be 
Table 1 Summary of Study Designs of Articles Retrieved

\begin{tabular}{|c|c|c|c|}
\hline $\begin{array}{l}\text { Level of } \\
\text { evidence }\end{array}$ & Study design & $\begin{array}{l}\text { Number } \\
\text { of results }\end{array}$ & Study authors \\
\hline \multirow[t]{5}{*}{$1 b$} & \multirow{5}{*}{$\begin{array}{l}\text { Randomized } \\
\text { controlled trial }\end{array}$} & \multirow[t]{5}{*}{5} & Beselga et $\mathrm{al}^{3}$ \\
\hline & & & Makofsky et $\mathrm{al}^{5}$ \\
\hline & & & Méndez-Sánchez et $\mathrm{al}^{6}$ \\
\hline & & & Walsh and Kinsella ${ }^{7}$ \\
\hline & & & Yildırım et $\mathrm{al}^{8}$ \\
\hline
\end{tabular}

effective for treating hip ROM asymmetries. Therefore, it may be clinically useful for clinicians to utilize the MC MWM techniques to address hip ROM asymmetries.

\section{Strength of Recommendation}

Level $1 \mathrm{~b}$ evidence exists supporting mobilizations as effective techniques for short-term improvements in patient perceived pain, ROM, and patient function. Although these studies were high quality (level 1), the strength of evidence supporting the longterm effects of novel hip mobilizations is questionable.

\section{Search Strategy}

\section{Terms Used to Guide Search Strategy}

A computerized search was completed in April and May 2016 (see Figure 1). The search terms used were as follows:

- Patient/Client group: healthy or non-surgical population and a decrease in hip ROM

- Intervention/Assessment: hip mobilization or mobilisation or mulligan concept

- Comparison: control or other treatments

- Outcome: hip internal range of motion or hip external range of motion or hip-flexion ROM or patient function or pain

\section{Sources of Evidence Searched}

- PubMed

- Medline

- CINAHL

- SPORTDiscus

- EBSCOhost

- Google Scholar

- Cross Referencing

\section{Inclusion and Exclusion Criteria}

\section{Inclusion Criteria}

- Studies that compared traditional hip therapeutic exercise (including 1 or more of thermotherapy, stretching, modalities, or strengthening) or sham mobilization or a hip mobilization

- Limited to publications within the past 10 years (2007-2016)

- Limited to the English language

- Patients who were diagnosed with limitations in hip ROM or decreased strength at the hip
- Limited to humans

- Limited to level 2 evidence or higher

\section{Exclusion Criteria}

- Studies that included participants with postoperative surgeries of hip, knee, or ankle

- Studies that did not incorporate or directly compare mobilizations of the hip or therapeutic exercise or stretching of the hip

- Studies that included therapeutic interventions other than manual therapy (eg, cortisone injections, medications, surgeries)

\section{Results of Search}

Five studies met the established inclusion criteria and were categorized as presented in Table 1 (based on levels of evidence, Centre for Evidence-Based Medicine, 2011). ${ }^{9}$

\section{Best Evidence}

Our search strategy identified 5 applicable studies that were determined to be the best available evidence and were included in the critically appraised topic (Table 2). These studies were selected because each assessed novel manual therapy techniques of the hip joint and reported effects on hip ROM and patient function compared with either a traditional therapy (eg, stretching), to a sham treatment, or to no treatment. These studies were rated level $1 \mathrm{~b}$ based on the 2011 levels of evidence from the Centre for Evidence-Based Medicine.

\section{Implications for Practice, Education, and Future Research}

Research focused on limited hip ROM, and pain related to decreased ROM suggests a potential mechanistic relationship between this condition and long-term pathology, such as hip osteoarthritis, ${ }^{1-3,10}$ patellofemoral pain syndrome, ${ }^{10}$ or low back pain. ${ }^{11}$ A proposed mechanism of hip asymmetry may alter biomechanics and lead to varying pathologies long term. ${ }^{4,11}$ Therefore, it is imperative to identify strategies to treat and resolve decreased hip ROM or asymmetry. The 5 articles ${ }^{3,5-8}$ that met inclusion and were reviewed provided evidence that utilizing hip mobilizations was an effective short-term intervention compared with sham techniques and were clinically meaningful. In these studies, the researchers examined the effect of mobilizations on ROM, ${ }^{3,8}$ patient functional tests,,${ }^{6,7}$ and muscle torque. ${ }^{5}$ The results were statistically significant and produced meaningful effect sizes (Table 3 ). In addition to improving clinical-based outcomes, such as ROM (ie, hip flexion, hip internal rotation, and hip external rotation), patients reported outcomes improved from hip mobilizations..$^{3,5-8}$ However, the results of the studies did not suggest 1 favorable mobilization technique (ie, MC vs HVLA) over another at this time. ${ }^{3,5-8}$

Specifically, for ROM, Beselga et $\mathrm{al}^{3}$ reported a significant interaction for hip flexion and hip internal rotation ROM after the intervention of the MC MWM flexion and internal rotation technique compared with a sham group who received a simulated MC MWM, but the clinician did not apply a force or a glide. In this study, $100 \%$ of MC MWM $(n=20)$ and $55 \%$ of sham $(n=11)$ groups experienced an increase in hip flexion of more than the minimal detectable change of $1.11^{\circ}$ and was clinically meaningful 


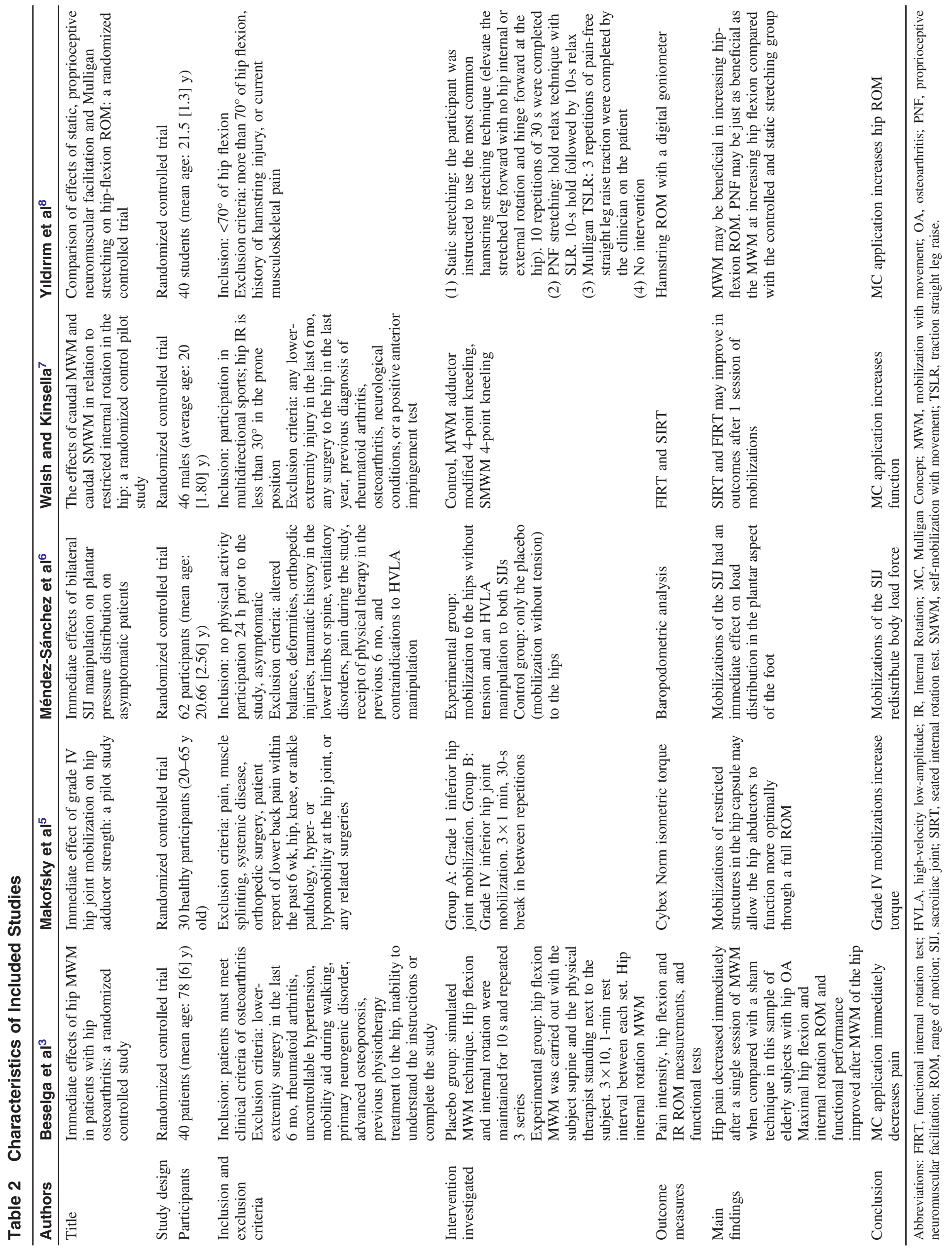




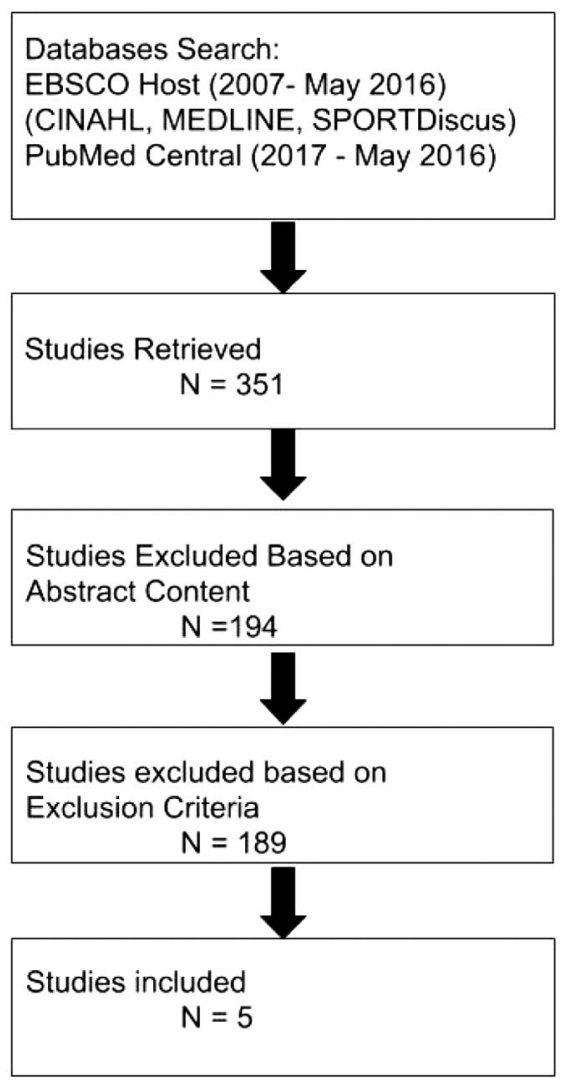

Figure 1 - Computerized search diagram, 2016.

(Cohen's $d=0.6) .{ }^{3}$ In addition, $80 \%$ of the MC MWM $(\mathrm{n}=16)$ and $20 \%$ of the sham $(\mathrm{n}=4)$ groups experienced an increase in hip internal rotation of $4.4^{\circ}$, which was greater than the minimal detectable change of $0.55^{\circ}$ and was clinically meaningful (Cohen's $d=1.4) .^{3}$ When MC MWMs were compared with stretching, Yıldırım et $\mathrm{al}^{8}$ found a significantly greater acute ROM increase in hip flexion when the MC MWM traction straight leg raise was used compared with static stretching or no treatment; however, a significant difference was not found between the proprioceptive neuromuscular facilitation group and the MC MWM traction straight leg raise group. Each of these studies identified a statistically significant improvement in ROM following the use of MC MWM techniques, but did not compare the effectiveness of MC techniques to traditional joint mobilizations or assess the long-term effectiveness of the techniques.

Mobilizations may also be effective for improving patient functional outcomes. Méndez-Sánchez et $\mathrm{al}^{6}$ found sacroiliac joint mobilizations (HVLA) produced an immediate effect on pressure load and weight distribution of the body when comparing the experimental group to a control group (a placebo load). ${ }^{6}$ Due to the sacroiliac joints playing a role in load distribution while standing, altering weight distribution through a mobilization may prevent or improve patient functional outcomes in pathologies resulting from asymmetrical loading. ${ }^{6}$ There was a significant effect on foot load distribution $(P=.03)$ and foot weight distribution $(P=.01)$ set at a 95\% confidence interval. ${ }^{6}$ Walsh and Kinsella ${ }^{7}$ also found that clinician-applied and patient-applied MC MWMs resulted in improvement in patient functional tests after 1 session when compared with a control group. Improved activation of the gluteus maximus muscle may account for the increase in functional ROM, which may explain the significant improvement in ROM during the functional internal rotation test, but not the seated internal rotation test. ${ }^{7,13}$ The results of the studies suggest that the use of MC MWM may be beneficial for improving patient functional outcomes.

To assess the effectiveness of various mobilization techniques, Makofsky et $\mathrm{al}^{5}$ compared different grades of joint mobilization in healthy patients who were randomly assigned to a specific intervention group. The control group received a grade I inferior hip joint mobilization, whereas the experimental group received a grade IV inferior hip joint mobilization. Both groups received 1 set of 3 repetitions of 1 minute with a 30 -second break

\section{Table 3 Reported Effect Sizes by Study}

\begin{tabular}{|c|c|c|}
\hline Source & Cohen's $d^{\mathrm{a}}$ effect size & Comparison \\
\hline Beselga et $\mathrm{al}^{3}$ & 0.6 & $\begin{array}{l}\text { Lateral MWM glide with hip flexion vs no glide with hip flexion on hip internal rotation } \\
\text { improvement }\end{array}$ \\
\hline Beselga et $\mathrm{al}^{3}$ & 1.2 & $\begin{array}{l}\text { Lateral MWM glide with hip flexion vs no glide with hip flexion on NPRS for hip pain } \\
\text { decrease }\end{array}$ \\
\hline Makofsky et $\mathrm{al}^{5}$ & 0.7 & $\begin{array}{l}\text { Torque increase of hip adductors after grade IV hip mobilization vs grade } 1 \text { hip } \\
\text { mobilization }\end{array}$ \\
\hline Méndez-Sánchez et al ${ }^{6}$ & $\begin{array}{l}0.55 \text { (weight), } 0.09 \text { (LFF load), } \\
0.63 \text { (LHF load), } 0.09 \text { (RFF load), } \\
0.65 \text { (RHF load), } 0.47 \text { (LF and } \\
\text { RF load) }\end{array}$ & $\begin{array}{l}\text { HVLA manipulation to SIJs was performed vs mobilization of the hips without tension } \\
\text { on location of pressure point }\end{array}$ \\
\hline Walsh and Kinsella ${ }^{7}$ & $\begin{array}{l}\text { SIRT: } 0.43 \text { (MWM), } 0.81 \\
\text { (SMWM); FIRT: } 1.64 \text { (MWM), } \\
0.40\end{array}$ & $\begin{array}{l}\text { MWM with hip caudal glide vs SMWM and no treatment caudal glides on hip IR } \\
\text { increase }\end{array}$ \\
\hline Yildırım et al ${ }^{8}$ & $\begin{array}{l}0.94 \text { (static stretching), } 2.15 \\
\text { (PNF stretching), } 2.21 \text { (Mulligan } \\
\text { TSLR), } 0.01 \text { (no intervention) }\end{array}$ & Mulligan TSLR vs PNF, vs control, vs static stretching on ROM increase \\
\hline $\begin{array}{l}\text { Abbreviations: HVLA, his } \\
\text { FIRT, functional internal } \\
\text { range of motion; SIRT, se } \\
\text { interpretation of the strengt } \\
0.5 \text {, and large }=0.8)^{12}\end{array}$ & $\begin{array}{l}\text { locity low amplitude; LF, Left Foot; } \\
\text { on test; MWM, mobilization with m } \\
\text { internal rotation test; SIJ, sacroiliac } \\
\text { the relationship: }{ }^{\text {aCohen's } d \text { focuses or }}\end{array}$ & $\begin{array}{l}\text { FF, Left Forefoot; LHF, Left Hind Foot; RF, Right Foot; RFF, Right Forefoot; RHF, Right Hind Foot; } \\
\text { vement; NPRS, Numeric Pain Rating Scale; PNF, Proprioceptive Neuromuscular Facilitation; ROM, } \\
\text { oint; SMWM, self-mobilization with movement; TSLR, Traction Straight Leg Raise. Note: General } \\
\text { the magnitude of difference. A } d \text { of } 0.5 \text { means the groups differ by } 1.5 \text { of a SD }{ }^{12} \text { (small }=0.2 \text {, medium }=\end{array}$ \\
\hline
\end{tabular}


between repetitions. The participants had a 15-minute break and then retested peak hip abductor torque values on the Cybex Norm dynamometer. The 1 set of 3 repetitions within the control group resulted in a 2.33 - $\mathrm{ft}$ lb improvement, which exceeded the calculated minimal detectable change of $1.88 \mathrm{ft} 1 \mathrm{~b} .^{5}$ This was a significant increase in torque compared with the premeasurement and postmeasurement between the experimental group and the control group of $t=1.024(P=.31) .^{5}$ Postintervention between group comparisons indicated an increase in hip abductor torque for the experimental group. The subjects were positioned in the right-side lying position with the hip abducted to $45^{\circ}$; with the hip in this position, the capsuloligamentous structures were put on a stretch. ${ }^{5}$ Mobilizations of restricted capsuloligamentous structures in the inferior hip capsule may allow the hip abductors to function more optimally through a full ROM. ${ }^{5}$ The researchers concluded that a joint mobilization may decrease the restriction in capsuloligamentous structures, which allows for greater joint ROM. ${ }^{5}$

One challenge for the use of mobilizations on the hip joint is the complexity of the region. With over 45 muscles attaching on the hip, ${ }^{10}$ the source of pain/limitation can often be misdiagnosed. Although all of the studies included in this critically appraised topic incorporated a type of mobilization, the specific types of mobilizations varied. The use of mobilizations has an immediate effect of improving hip joint ROM and is recommended to be incorporated into patient treatments where hip ROM limitation and/or pain is present. ${ }^{3,5-8}$ Beselga et al, ${ }^{3}$ Walsch and Kinsella, ${ }^{7}$ and Yildırım et $\mathrm{al}^{8}$ recommended use of the MC over other techniques, although all 3 studies used different MC techniques.

Clinicians can use the findings from this critically appraised topic as a general recommendation when incorporating hip mobilizations, attempting to improve patient outcomes. Patients who suffer from decreased hip ROM and pain may benefit from the application of either MC mobilizations or HVLA manipulations. However, the use of different interventions (MWMs and joint mobilizations) and inconsistent methodology make comparisons difficult across these 5 studies; thus, a recommendation on the most effective mobilization intervention or a gold standard to increase hip ROM is not recommended at this time. Future research should include well-designed prospective studies (eg, randomized controlled studies) investigating the effects of mobilizations on ROM at the hip for stratified populations. Recommended populations to study include active, competitive patients with healthy asymmetries of hip ROM and patients with specific pathologies limiting hip ROM. Future studies are also warranted to investigate the effects of specific MC MWM techniques on the hip joint ROM to determine model treatment techniques for improving hip ROM.

\section{References}

1. Sacks J, Luo Y, Helmick C. Prevalence of specific types of arthritis and other rheumatic conditions in the ambulatory health care system in the United States, 2001-2005. Arthrit Care Res. 2010;62(4): 460-464. doi:10.1002/acr.20041

2. Lawrence RC, Felson DT, Helmick CG. Estimates of the prevalence of arthritis and other rheumatic conditions in the United States. Part II. Arthritis Rheum. 2008;58(1):26-35. PubMed ID: 18163497 doi: 10.1002/art.23176

3. Beselga C, Neto F, Alburquerque-Sendín F, Hall T, OliveiraCampelo N. Immediate effects of hip mobilization with movement in patients with hip osteoarthritis: a randomized controlled trial. Man Ther. 2015;22:80-85. PubMed ID: 26559319 doi:10.1016/ j.math.2015.10.007

4. Nam CW, Park SI, Yong MS, Kim YM. Effects of the MWM technique accompanied by trunk stabilization exercises on pain and physical dysfunctions caused by degenerative osteoarthritis. J Phys Ther Sci. 2013;25(9):1137-1140. PubMed ID: 24259931 doi:10.1589/jpts.25.1137

5. Makofsky H, Panicker S, Abbruzzese J, et al. Immediate effect of grade IV inferior hip joint mobilization on hip abductor torque: a pilot study. J Man Manip Ther. 2007;15(2):103-110. PubMed ID: 19066650 doi:10.1179/106698107790819927

6. Méndez-Sánchez R, González-Iglesias J, Sánchez-Sánchez JL, Puente-González AS. Immediate effects of bilateral sacroiliac joint manipulation on plantar pressure distribution in asymptomatic participants. J Altern Complem Med. 2014;20(4):251-257. doi:10.1089/ acm.2013.0192

7. Walsh R, Kinsella S. The effects of caudal mobilization with movement (MWM) and caudal self-mobilization with movement (SMWM) in relation to restricted internal rotation in the hip: a randomized control pilot study. Man Ther. 2016;22:9-15. PubMed ID: 26995777 doi:10.1016/j.math.2016.01.007

8. Yıldırım MS, Ozyurek S, Tosun OÇ, Uzer S, Gelecek N. Comparison of effects of static, proprioceptive neuromuscular facilitation and Mulligan stretching on hip flexion range of motion: a randomized controlled trial. Biol Sport. 2016;33(1):89-94. PubMed ID: 26929476 doi: $10.5604 / 20831862.1194126$

9. OCEBM Levels of Evidence Working Group. (2011). The Oxford 2011 Levels of Evidence. Oxford Centre for Evidence-Based Medicine. http://www. cebm. net/index. aspx? o= 5653

10. Felson DT, Zhang Y. An update on the epidemiology of knee and hip osteoarthritis with a view to prevention. Arthritis Rheum. 1998; 41(8):1343-1355. PubMed ID: 9704632 doi:10.1002/1529-0131 (199808)41:8<1343::AID-ART3>3.0.CO;2-9

11. Almeida GPL, de Souza VL, Sano SS, Saccol MF, Cohen M. Comparison of hip rotation range of motion in Judo athletes with and without history of low back pain. Man Ther. 2012;17(3): 231-235. PubMed ID: 22281524 doi:10.1016/j.math.2012.01.004

12. Cohen J. Statistical Power and Analysis for the Behavioral Sciences. 2nd ed. Hillsdale, NK: Lawrence Erlbaum; 1988.

13. Yerys S, Makofsky H, Bryd C, Pennachin J, Chinkay J. Effects of mobilization of the anterior capsule on gluteus maximus strength. $J$ Man Manip Ther. 2002;10(4):218-224. doi:10.1179/106698 102790819085 